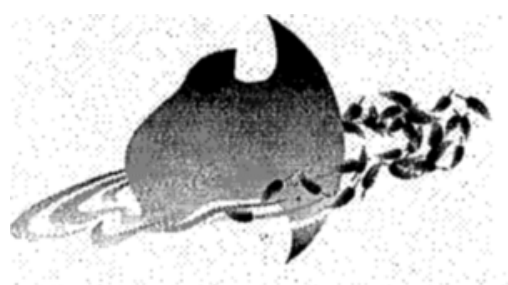

\title{
Welcome from the Outdoor Council of Australia
}

\author{
Zoe Herbert
}

The Outdoor Council of Australia has a giant task ahead of it with the needs and issues of the industry coming to the fore across many sectors. Surviving insurance premiums, land access issues, and a litigious climate are significant obstacles for all - from private enterprise, to volunteers, to educators and participants.

The OCA is committed to the evolution and protection of education and enjoyment in the outdoors. We want to keep individuals and groups enjoying and learning in Australia's beautiful wilderness. We honour the aims of our members, cherish the outdoors itself, and are committed to sensible sustainable practices.

In its first year of operation, in addition to the trials faced by any organization in the development stage, OCA has supported several key initiatives. These include the rollout of the National Outdoor Leadership Registration Scheme (NOLRS), facilitating the proposed merger of two key organizational accreditation schemes (Australian Camping Association and the Outdoor Recreation Industry Council of NSW) into one national one, continuing the publication of the Australian Journal of Outdoor Education, and bringing the state organizations together for open dialogue on issues of national importance. A sub-committee with a representative from each state has been formed to oversee implementation issues with the NOLRS scheme and a sub-committee for the national accreditation program has also been devised.

The OCA Board are a dedicated and experienced collection of individuals from across the entire industry who are keen to make a fundamental difference and to be of real service to its members. It has been a privilege to work alongside them and I have every confidence that together the Board will move the professional practice in the outdoors forwards to new success. I look forward to you joining OCA in preserving and developing our industry and profession.

Zoe Herbert

President. 